\title{
Compositional characteristics and oxidative stability of chia seed oil (Salvia hispanica L)
}

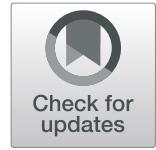

Abrehem Abad and Fereidoon Shahidi

\begin{abstract}
Fatty acid composition and triacylglycerols (TAG) profile of chia seed oil were determined. The main fatty acids present in the tested oil were a-linolenic acid $(L n, 61.1 \%)>$ linoleic acid $(L, 16.6 \%)>$ palmitic acid $(P, 6.7 \%)>$ oleic acid $(\mathrm{O}, 6.0 \%)>$ stearic acid $(\mathrm{S}, 3.2 \%)$. Five major triacylglycerols in chia oil were $\operatorname{LnLnLn}, \operatorname{LnLLn}, \mathrm{LnLnP}$, LnOLn, and LLLn and these contributed more than $76 \%$ to the total. The oxidative stability under autoxidative and photooxidative conditions before and after the removal of their minor components was also determined. In addition, tocols, chlorophylls and carotenoids were measured in the oil. Oil samples were stripped of their minor components by using a facile silicic acid and charcoal in one pot rather than in a column. Storage under Schaal oven condition and photooxidation were also monitored for both crude oil (non-stripped) and stripped oil using stationary phase material. Total tocopherol contents were in the order of $\beta-/ \gamma^{-} 282.68, \delta-47.44$, and a-tocopherols $10.94 \mathrm{mg} / \mathrm{kg}$ of oil. Stripping removed all the minor components including tocopherols, chlorophylls and carotenoids. Oxidative stability of the tested seed oil was primarily affected by its composition of fatty acids, triacylglycerols, minor components, and storage conditions.
\end{abstract}

Keywords: Chia seed oil, Fatty acids, Triacylglycerols, Tocopherols, Pigments, Chlorophylls, Carotenoids, Oxidative stability

\section{Introduction}

There are around 900 species in the family Lamiaceae, under the Salvia genus, and these are utilized around the world as folk medicine and flavoring agents ( $\mathrm{Lu} \&$ Foo 2002). This annual plant reaches about 1 metre in height with serrated leaves of $4-8 \mathrm{~cm}$ long and $3-5 \mathrm{~cm}$ wide with hermaphrodite flowers (Haytowitz et al. 2011). The seeds of Salvia hispanica L., generally known as "chia sage", "chia", and "Spanish sage" were an essential staple food, medicine, and source of oil in the pre-Columbian ages (Reyes-Caudillo et al. 2008). Southern Mexico and northern Guatemala are the native places for chia plant (Ayerza 1995). Chia is marketed in South America and Canada as a health food commodity (Ayerza and Coates 2011; Segura-Campos et al. 2014). European Union (2009) approved chia as a novel food which could also

\footnotetext{
* Correspondence: fshahidi@mun.ca

Department of Biochemistry, Memorial University of Newfoundland, St. John's, NL A1B 3X9, Canada
}

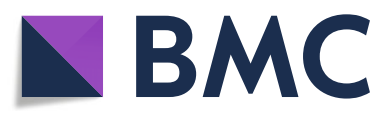

(- The Author(s). 2020 Open Access This article is licensed under a Creative Commons Attribution 4.0 International License, which permits use, sharing, adaptation, distribution and reproduction in any medium or format, as long as you give

appropriate credit to the original author(s) and the source, provide a link to the Creative Commons licence, and indicate if changes were made. The images or other third party material in this article are included in the article's Creative Commons licence, unless indicated otherwise in a credit line to the material. If material is not included in the article's Creative Commons licence and your intended use is not permitted by statutory regulation or exceeds the permitted use, you will need to obtain permission directly from the copyright holder. To view a copy of this licence, visit http://creativecommons.org/licenses/by/4.0/.

be used up to $5 \%$ in bread making (Commission of the European Communities 2009). It contains a high amount of $\alpha$-linolenic acid (C18:3n-3, ALA) and vitamins (Rincon-Cervera et al. 2016). Valenzuela et al. (2015) reported that chia oil intake leads to conversion of its $\alpha$-linolenic acid (ALA) to eicosapentaenoic acid (EPA) of erythrocytes in pregnant women and an increase of the docosahexaenoic acid (DHA) in their milk.

Chia seeds and oil contain a relatively high amount of natural antioxidants such as tocopherols and carotenoids, as well as phytosterols (Ixtaina et al. 2011). The phenolic compounds in chia include caffeic acid, chlorogenic acid, myricetin, kaempferol, and quercetin (Reyes-Caudillo et al. 2008; Capitani et al. 2012; Rahman et al. 2017). These phenolics play an important role in protecting against many diseases and promoting human health (Nijveldt et al. 2001).

The chemical characterization of chia seed and chia oil from some countries and regions have previously been reported (Ayerza and Coates 2011; Ixtaina et al. 2011; 
Capitani et al. 2012; Reyes-Caudillo et al. 2008; Alfredo et al. 2009). However, the triacylglycerol profile of chia seed oil has not yet been studied and there is little information available on its oxidative stability with respect to the effect of its endogenous antioxidants and minor components.

The objectives of the present study were to examine the fatty acid composition, triacylglycerols (TAG) profile and the minor components (tocopherols, chlorophylls and carotenoids) in both stripped and non-stripped chia seed oil, In addition, the effects of the minor components on the oxidative stability of oils under autoxidative and photooxidative conditions were monitored.

\section{Materials and methods Materials}

Commercial samples of chia seeds (Salvia hispanica L) were bought from Costco Wholesale, St. John's, NL, Canada. Standard of fatty acid methyl esters (FAMEs, GLC-461) were obtained from Nu-Check (Elysian, MN, USA). Standards of tocopherols, activated charcoal, silicic acid powder (mesh size: 100-200), and 2thiobarbituric acid were purchased from Sigma-Aldrich (Mississauga, ON, Canada). Hexane, methanol, ethanol, acetonitrile, sulphuric acid, isooctane, isopropanol, 1butanol and all other chemicals were procured from Fisher Scientific Co. (Nepean, ON, Canada), and used without any further purification. All solvents and chemicals were of analytical grade.

\section{Methods}

\section{Hexane extraction of oil}

Seed samples $(50 \mathrm{~g})$ were ground into a fine powder and then extracted with $250 \mathrm{~mL}$ of hexane using a Waring blender (model 51BL30, WARING commercial, Phoenix, AZ, USA) for 2 min (Miraliakbari and Shahidi 2008). The mixture was filtered through a Whatman No. 1 filter paper by using a Buchner funnel. The residue was re-extracted five times, and the solvent was removed via rotary evaporatoration at $40{ }^{\circ} \mathrm{C}$. The extracted oil was weighed, flushed with nitrogen, and kept at $-80^{\circ} \mathrm{C}$ until use.

\section{Stripping of chia seed oils}

The seed oils from the chia were stripped of their minor constituents according to the simplified stripping method described elsewhere (Abad and Shahidi 2020) using silicic acid and charcoal which are commonly used as a stationary phase material in the column stripping method (Li et al. 2016). Approximately $60 \mathrm{~mL}$ of oil were mixed with $60 \mathrm{~mL}$ of hexanes and added to $90 \mathrm{~g}$ of activated silicic acid and $45 \mathrm{~g}$ of charcoal while stirring for $2 \mathrm{~h}$ in a fume hood at $27.5^{\circ} \mathrm{C}$ under a blanket of nitrogen, followed by filtration. About $200 \mathrm{~mL}$ of hexane was used to wash the solids during filtration. The solvent from the stripped oil was removed by evaporation under vacuum at $40{ }^{\circ} \mathrm{C}$. The resulting stripped oil was flushed with nitrogen, weighed and stored at $-80^{\circ} \mathrm{C}$ until use (Abad and Shahidi 2020).

\section{Fatty acid composition}

The method used for fatty acid composition analysis of the non-stripped and stripped chia seed oils followed transmethylation with subsequent gas chromatographyflame ionization detection (GC-FID) (Wanasundara and Shahidi 1997) as reported elsewhere (Abad and Shahidi: Autoxidative and photooxidative stability of camelina and sophia seed oils as affected by their fatty acids, triacylglycerols and minor components, forthcoming). The results were expressed as the weight percentage of each fatty acid in the total amount.

\section{Triacylglycerol (TAG) profiles}

TAGs in chia seed oils were tested according to the method of Lísa and Holcapek (2008) as detailed by Li et al. (2016) using high-performance liquid chromatography-photodiode array detectionatmospheric pressure chemical ionization-mass spectrometry (HPLC-DAD-APCI-MS). A mixture of isopropanol and acetonitrile $(1: 1, \mathrm{v} / \mathrm{v})$ was used to dissolve the oil and to obtain a $3 \%(\mathrm{w} / \mathrm{v})$ solution. For the separation, a C-18 column was used $(4.6 \mathrm{~mm} \times 250 \mathrm{~mm})$ with the following details ( 0 min, $100 \%$ A; 106 min, 31\% A; 120 min, $100 \% \mathrm{~A}$ ).

\section{Measurement of minor components} Measurement of pigments (chlorophylls and carotenoids) Pigments present in the non-stripped and stripped chia oilseed samples were determined by measuring the absorbance at 550-710 for chlorophylls and $430-460 \mathrm{~nm}$ for carotenoids (Abuzaytoun and Shahidi 2006a). The samples were dissolved in hexane $(1: 1, \mathrm{v} / \mathrm{v})$ and placed in quartz cuvettes. The absorbance was subsequently read using an 8453A UV-visible Agilent spectrophotometer (Palo Alto, CA, USA).

\section{Determination of tocopherols}

The tocopherols in chia oil samples were analyzed as described elsewhere (Li et al. 2016), using an Agilent 1100 HPLC unit (Palo Alto, CA, USA). Samples $(0.1 \mathrm{~g})$ were dissolved in $2 \mathrm{~mL}$ of methanol/acetonitrile/isopropanol (41:59:300, v/v/v). Meanwhile, standards were prepared by dissolving a known amount of tocopherol in the same solvent with serial dilution.

The separation of tocopherols was achieved using a C18 column $(4.6 \mathrm{~mm} \times 250 \mathrm{~mm}$, Agilent $)$ and a gradient elution with methanol/acetonitrile/isopropanol mobile phase (flow of $0.8 \mathrm{~mL} / \mathrm{min}$ ); the fractions were detected 
at $295 \mathrm{~nm}$, as explained elsewhere (Abad and Shahidi 2020). The tocopherol concentration in the tested oil was calculated using a standard curve and results were expressed as $\mathrm{mg} / \mathrm{kg}$ of oil.

\section{Oxidative stability tests under accelerated oxidation conditions using Schaal oven condition or fluorescent light}

Preparation of samples for Schaal oven and photooxidation tests Oxidative stability of oils was evaluated under Schaal oven conditions or fluorescent light for both non-stripped and stripped chia seed oils. The Schaal oven conditions were used to examine the oxidative stability of non-stripped and stripped chia seed oils at $60^{\circ} \mathrm{C}$ for $1,3,5$, and 7 days (Li et al. 2016). For the photooxidation studies, oil samples were placed in a rectangular polyethylene box $(70 \mathrm{~cm}$ long, $35 \mathrm{~cm}$ wide, and $25 \mathrm{~cm}$ high), two cool white fluorescent lights have suspended $10 \mathrm{~cm}$ above the oil samples (Abuzaytoun and Shahidi 2006a). The temperature in the chamber was maintained at $28.5+/-1{ }^{\circ} \mathrm{C}$, while the level of fluorescent radiation was at 2650 Lux. After 1, 3, 6, 12, 24, 48 , and $72 \mathrm{~h}$, samples were flushed with nitrogen, and then kept at $-80^{\circ} \mathrm{C}$ until tested for oxidative stability determination ( $\mathrm{Li}$ et al. 2016).

The oxidative stability of non-stripped and stripped oils was evaluated for primary oxidation by determining conjugated dienes (CD) and secondary oxidation by monitoring 2-thiobarbituric acid-reactive substances (TBARS).

The technique used to determine the $(\mathrm{CD})$ was described by Abuzaytoun and Shahidi (2006b). Roughly $0.02-0.04 \mathrm{~g}$ of sample was weighed and transferred to the volumetric flask $(25 \mathrm{~mL})$. The oil samples were then dissolved in isooctane and brought to the mark in the volumetric flask. A spectrophotometer and a Hewlett-Packard 8456A diode array detector were used and the absorbance at $234 \mathrm{~nm}$ was read by employing a $10-\mathrm{mm}$ Hellma quartz cell. To compute the conjugated dienes values, the equation below was used.

$$
\mathrm{CD}=\mathrm{A} /(\mathrm{Cxd})
$$

Where $\mathrm{C}$ is the concentration of the solution $(\mathrm{g} / 100$ $\mathrm{mL}$ ), $\mathrm{A}$ is the absorbance of the solution at $234 \mathrm{~nm}$, and $d$ the length of the cell (Abuzaytoun and Shahidi 2006b).

For determination of 2-thiobarbituric acid-reactive substances (TBARS), $0.05-0.20 \mathrm{~g}$ of sample was transferred to $25 \mathrm{~mL}$ volumetric flask (Abuzaytoun and Shahidi 2006b). 1-Butanol was used to dissolve the oil and brought to the mark. In a dry test tube, $5 \mathrm{~mL}$ of the mixture were mixed with the same amount of 2-TBA solution (200 mg 2-TBA dissolved in $100 \mathrm{~mL}$ 1-butanol) and placed in a water bath $\left(95^{\circ} \mathrm{C}\right)$ for $2 \mathrm{~h}$ (Abuzaytoun and Shahidi 2006b). The intensity of the coloured complex was read at $532 \mathrm{~nm}$ using a Hewlett-Packard 8452A diode array spectrophotometer.

\section{Statistical analysis}

All experiments were carried out in triplicate. ANOVA, a single-way evaluation of variance, together with Tukey's standardized test were conducted at $p<0.05$ (Abuzaytoun and Shahidi 2006a). ANOVA and Tukey's standardized test were utilized to evaluate the significance of differences which existed between the values.

\section{Results and discussion}

\section{Fatty acid profiles of chia seed oil}

Table 1 summarizes the major fatty acid profiles of nonstripped and stripped of chia seed oils. These included mainly $\alpha$-linolenic (C18:3n-3, 61.2\%), linoleic (C18:2n-6), oleic (18:1), palmitic (C16:0) and stearic (C18:0) acids. Chia seed oil tested contained $78.3 \%$ polyunsaturated fatty acids (PUFA), and only $10.3 \%$ of saturated fatty acids. These results agree with those reported in earlier studies (Coates and Ayerza 1998; Ayerza and Coates 2004; da Silva Marineli et al. 2014). Due to the health effects of PUFA (Ganesan et al. 2014), inclusion of chia seed oil in the human diet is considered beneficial.

The small differences between fatty acid profiles in this study and those in the literature may be due to the existing differences in the source, storage conditions, and other variables such as environmental conditions related to soil type, light, temperature, and available nutrients. In particular, Ayerza (1995) reported that the variations in the contents of oil as well as oleic, linoleic, and linolenic acids were affected by the location. However, another study found that chia seeds which grew in

Table 1 Major of fatty acid composition of non-stripped and stripped of chia seed oil ${ }^{1,2}$

\begin{tabular}{|c|c|c|}
\hline$\overline{F A}(\%)$ & $\mathrm{NCh}$ & $\mathrm{SCh}$ \\
\hline C16:0 & $6.7 \pm 0.1^{a}$ & $6.6 \pm 0.2^{a}$ \\
\hline C18:0 & $3.2 \pm 0.1^{a}$ & $3.4 \pm 0.1^{a}$ \\
\hline C18:1 & $6.0 \pm 0.1^{\mathrm{a}}$ & $6.3 \pm 0.1^{\mathrm{a}}$ \\
\hline C18:2 & $16.6 \pm 0.0^{a}$ & $16.4 \pm 0.3^{a}$ \\
\hline C18:3 & $61.1 \pm 0.9^{\mathrm{a}}$ & $61.0 \pm 0.9^{a}$ \\
\hline C20:0 & $0.8 \pm 0.0^{a}$ & $0.8 \pm 0.0^{a}$ \\
\hline C20:1 & $0.8 \pm 0.0^{\mathrm{a}}$ & $0.8 \pm 0.0^{\mathrm{a}}$ \\
\hline$C 20: 2$ & $0.6 \pm 0.0^{\mathrm{a}}$ & $0.6 \pm 0.0^{a}$ \\
\hline C22:1 & - & - \\
\hline$\Sigma$ SFA & 10.8 & 10.8 \\
\hline$\Sigma M U F A$ & 6.9 & 7.1 \\
\hline$\Sigma$ PUFA & 78.3 & 78.0 \\
\hline
\end{tabular}

${ }^{1}$ Values are mean of triplicate determination \pm standard deviation. Values in the same row with different superscripts are significantly different $(P<0.05)$. ${ }^{2}$ Abbreviations: NCh Non-stripped chia seed oil, SCh Stripped chia seed oil 
different ecosystems in South America showed a significant difference in their oil contents, peroxide value, and fatty acid composition (Ayerza and Coates 2004). It is worth mentioning that the fatty acid profile in this study remained unchanged before and after the stripping of the oil by using the stripped oil by either the stationary phase $(2 \mathrm{~h})$ or column stripping (data not reported).

\section{Triacylglycerol composition of chia seed oil}

Table 2 summarizes the triacylglycerols (TAGs) of chia seed oil determined by high performance liquid chromatography (HPLC). These included trilinolenin (LnLnLn), linolenoyl-linoleoyl-linolenoylglycerol (LnLLn), linolenoyl-linolenoyl-palmitoylglycerol (LnLnP), linoleoyl-linoleoyl-linolenoylglycerol (LLLn), and linolenoyl-oleoyl- linolenoylglycerol (LnOLn). The results obtained here are in good agreement with the fatty acid profile of chia oil obtained by GC as reported in Table 1 which showed the dominance of the same fatty acids in both sets of data. The TAG profile of an oil provides useful information for direct use of the oil in food, pharmaceutical, and chemical industries (Haddad et al. 2006).

Neff et al. (1997) reported that the oxidative stability of an oil depends on its triacylglycerol composition. Furthermore, TAG can affect the functional properties of foods to which the oil is added, including the taste and texture quality of products (Bakowska-Barczak et al. 2009). Neff et al. (1993), as well as Neff et al. (1994) reported that TAG types such as LOO, LLO, POO, LOP, LOS, and OOO increased the oil stability; however, LnLP, LLLn, LLP, LLS, LnLO, and PLP decreased it. Thus, the results in Table 2 that show chia seed oil is rich in LnLLn, LnLnLn, LLLn, LnLnP, and LnOLn indicate its faster oxidative deterioration than other oils that are rich in oleic acid, for instance, mango seed kernel oil (Ali et al. 1985; Bakowska-Barczak et al. 2009).

\section{Tocols in stripped and non-stripped chia seed oils}

Table 3 summarizes the contents of tocols in stripped and non-stripped hexane-extracted chia seed oil. The total tocopherols in chia was $341.06 \mathrm{mg} / \mathrm{kg}$ of oil. Mainly $\beta-/ \gamma$-tocopherol (>82\%), followed by $\delta$-tocopherol $(47.44 \mathrm{mg} / \mathrm{kg})$ were present, while the content of $\alpha$ tocopherol was the lowest at $10.94 \mathrm{mg} / \mathrm{kg}(3.2 \%)$ among total tocopherols. Total amount of tocopherols in chia oils was in the range of those reported in the literature (238-427 mg/kg) (Ixtaina et al. 2011), but lower than those recorded in sunflower oil $(634.4 \mathrm{mg} / \mathrm{kg})$ and flaxseed oil $(588.5 \mathrm{mg} / \mathrm{kg}$ ) (Tuberoso et al. 2007). Shahidi and Shukla (1996) reported that high amounts of tocopherols are usually associated with high content of polyunsaturated fatty acids.
Table 2 Triacylglycerol (TAG) composition (relative concentration, \%) of non-stripped chia seed oil ${ }^{1,2,3}$

\begin{tabular}{|c|c|c|c|}
\hline$\overline{\mathrm{TAG}}$ & RT/Min & $(M+H) M W$ & $\mathrm{NCh}$ \\
\hline LnLnLn & 45.45 & 873 & $33.51 \pm 2.12^{\mathrm{a}}$ \\
\hline LnLLn & 52.61 & 875 & $20.25 \pm 1.75^{a}$ \\
\hline LLLn & 59.72 & 877 & $6.25 \pm 0.04^{\mathrm{a}}$ \\
\hline LnOLn & 61.06 & 877 & $6.48 \pm 0.05^{a}$ \\
\hline $\operatorname{Ln} \operatorname{LnP}$ & 62.57 & 851 & $9.55 \pm 0.14^{a}$ \\
\hline LLL & 64.67 & 879 & nd \\
\hline LnLMo & 65.4 & 865 & $0.28 \pm 0.00^{b}$ \\
\hline LLLn & 66.93 & 879 & $0.91 \pm 0.01^{b}$ \\
\hline OLLn & 67.49 & 879 & $3.35 \pm 0.03^{b}$ \\
\hline$L n L P$ & 69.5 & 853 & $4.30 \pm 0.10^{a}$ \\
\hline SLnLn & 70.73 & 879 & $4.34 \pm 0.07^{b}$ \\
\hline $\mathrm{C} 20: 2 \mathrm{LL}$ & 72.37 & 907 & nd \\
\hline OLL & 74.81 & 881 & $0.54 \pm 0.01^{c}$ \\
\hline OLnO & 75.13 & 881 & nd \\
\hline LLP & 75.49 & 855 & $1.83 \pm 0.02^{\mathrm{a}}$ \\
\hline LnOP & 76.12 & 855 & nd \\
\hline SLLn & 77.37 & 881 & $2.79 \pm 0.04$ \\
\hline PLnP & 79.39 & 829 & $0.64 \pm 0.03$ \\
\hline GLL & 79.85 & 909 & nd \\
\hline OLO & 83.94 & 883 & $0.51 \pm 0.01^{c}$ \\
\hline ОOP० & 84 & 857 & nd \\
\hline SLL & 85.04 & 883 & $0.68 \pm 0.01^{a}$ \\
\hline ALLn & 85.8 & 909 & nd \\
\hline OLP & 85.95 & 857 & $0.22 \pm 0.00$ \\
\hline GOLa & 86.73 & 831 & $0.61 \pm 0.02$ \\
\hline SOLn & 87 & 883 & nd \\
\hline BLLn & 87.7 & 937 & nd \\
\hline SLnS & 88.5 & 885 & nd \\
\hline PPP & 88.7 & 807 & nd \\
\hline LgLL & 91.31 & 967 & $0.19 \pm 0.00$ \\
\hline BLD & 93.65 & 941 & $0.19 \pm 0.00^{b}$ \\
\hline LgLO & 100.5 & 969 & nd \\
\hline C23:000 & 103 & 957 & nd \\
\hline LgOO & 105 & 971 & nd \\
\hline Total & & & 97.42 \\
\hline
\end{tabular}

${ }^{1}$ Values are means of triplicate determination \pm standard deviation. ${ }^{2}$ Values in the same row with different superscripts are significantly different $(p<0.05)$.

${ }^{3}$ Abbreviations: NCh Non-stripped chia seed oil, nd Not detected

It was demonstrated that column chromatographic stripping technique was able to totally remove tocopherols from borage oil (Khan \& Shahidi 2002). Furthermore, using the same method of stripping (column chromatographic), Abuzaytoun and Shahidi (2006a, 2006b) were able to entirely eliminate and remove the tocopherols in various types of oils including flax and 
Table 3 Tocol concentration ( $\mathrm{mg} / \mathrm{kg}$ of oil) in the original nonstripped and stripped chia seed oil ${ }^{1,2}$

\begin{tabular}{lll}
\hline Tocols & Non-stripped & Stripped \\
\hline a-tocopherol & $10.94 \pm 1.65^{\mathrm{a}}$ & $\mathrm{nd}^{\mathrm{b}}$ \\
$\beta / \gamma$-tocopherol & $282.68 \pm 1.21^{\mathrm{a}}$ & $\mathrm{nd}^{\mathrm{b}}$ \\
S-tocopherol & $47.44 \pm 1.21^{\mathrm{a}}$ & $\mathrm{nd}^{\mathrm{b}}$ \\
Total tocopherols & $341.06 \pm 4.07^{\mathrm{a}}$ & $\mathrm{nd}^{\mathrm{b}}$ \\
\hline
\end{tabular}

${ }^{1}$ Values are mean of triplicate determination \pm standard deviation. Values with different superscript in each row are significantly different from each other $(P<0.05){ }^{2}$ Abbreviation: $n d$ Not detected

hemp oils by conventional column stripping method. Recently, Abad and Shahidi (2020) used a new and simplified stripping method by mixing the oil with striping material diluted with eluting solvent for $2 \mathrm{~h}$ to remove the minor components from different oil samples and reported that the simplified method was successful in eliminating the minor components from the oil samples. Thus, the results in this study as given in Table 3 are in good agreement with the column stripping method in entirely eliminating the tocopherols from the tested oils.

\section{Pigments in stripped and non-stripped chia seed oils}

Pigments in chia oil, namely chlorophylls (detected between 600 and $710 \mathrm{~nm}$ ) and carotenoids (monitored between 430 and $460 \mathrm{~nm}$ ) (Blekas et al. 1995), were quantified using an 8453A UV-Visible spectrophotometer (Agilent Technologies, Palo Alto, CA, USA) (Abuzaytoun and Shahidi 2006a). The absorbance of nonstripped chia seed oil at $460 \mathrm{~nm}$ was 0.23 , which is much higher than that of 0.03 for its stripped counterpart. It is quite noticeable that stripping successfully removed all the pigments that were present (Fig. 1). This is in agreement with those from column striping in this work and those by $\mathrm{Li}$ et al. (2016) that reported all pigments including carotenoids and chlorophylls were removed by the column stripping process. Thus, the simplified stripping method employed in this work was effective for removing all the pigments present.

\section{Oxidative stability of non-stripped and stripped chia seed oil \\ Oxidative stability under schaal oven test conditions (CD \\ test)}

For practical purposes, all seed oils (stripped and nonstripped) were placed in an air-forced oven at $60^{\circ} \mathrm{C}$ during the Schaal oven test. Abou-Gharbia et al. (1996) reported that storage of oil for one day under Schaal oven conditions at $65^{\circ} \mathrm{C}$ was equivalent 1 month of storage at room temperature $\left(25^{\circ} \mathrm{C}\right)$. Furthermore, flavour scores of the oils stored for 4 days at $60^{\circ} \mathrm{C}$ agreed with those stored for 4 months at room temperature $\left(25^{\circ} \mathrm{C}\right)$ (Warner et al. 1989).

Stripped chia seed oil was less stable than its nonstripped counterpart under Schaal oven conditions (Fig. 2). This is due to the removal of antioxidative minor components that prevented the oxidation of the unsaturated fatty acids (UFA). Thus, antioxidants including tocopherols, carotenoids, and chlorophylls play a significant role in stabilizing non-stripped chia seed oil. Chia seed oil contains a high amount of UFA, therefore, free radical chain reactions that may occur can be

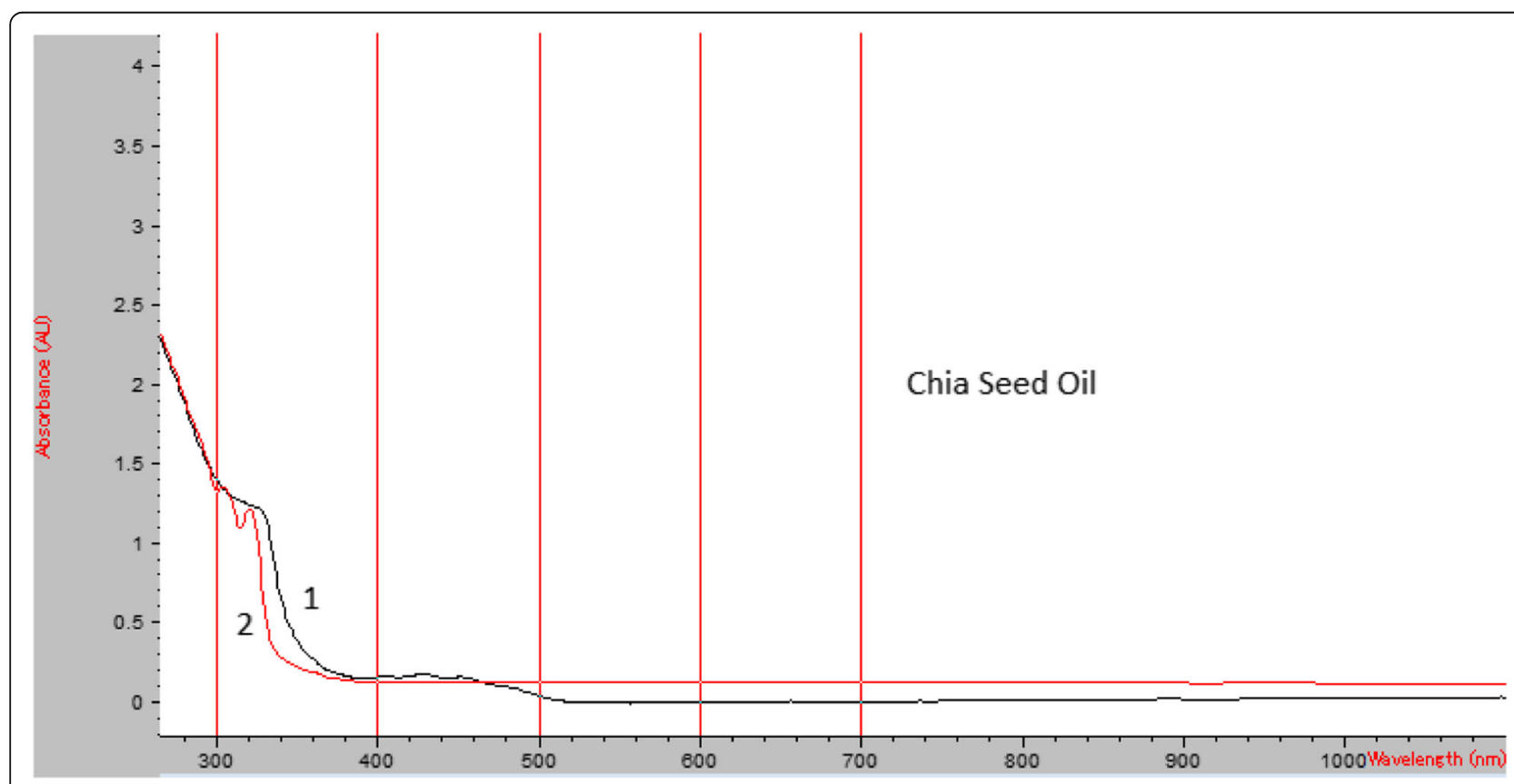

Fig. 1 Visible spectra of pigments in seed oils (1) original oil, (2) stripped oil 


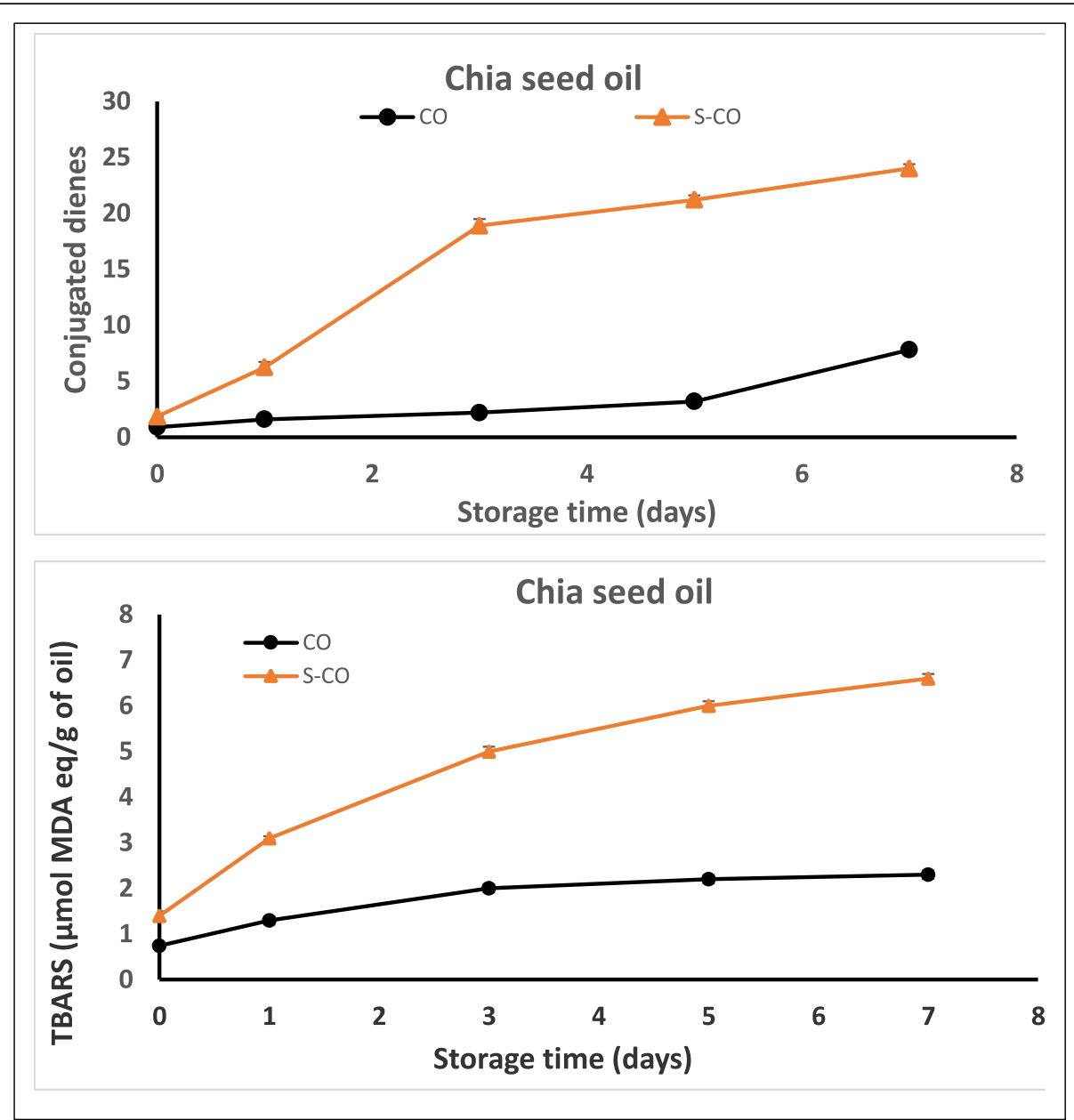

Fig. 2 Conjugated dienes and thiobarbituric acid reactive substances (MDA equivalents) of crude oil (CO) and stripped oil (S-CO) of chia oil seed during a 7-day storage at $60^{\circ} \mathrm{C}$ under Schaal oven conditions $(p>0.05)$

stopped by the action of the antioxidants present (tocopherols, carotenoids, and chlorophylls) (Porter et al. 1995). However, stripped chia oils reflected similar CD trends to its non-stripped counterpart.

Secondary oxidation products of chia seed oil were determined by monitoring the thiobarbituric acid reactive substances (TBARS). Determination of TBARS is based on the colour intensity of the reaction between secondary oxidation products of PUFA, including malondialdehyde (MDA), and TBA; the values of TBARS are expressed as mmol MDA eq/ $\mathrm{g}$ of oil.

Stripped and non-stripped TBARS of chia oils shared a similar trend with that of conjugated dienes formation (Fig. 2). The stripped chia oils were less stable than nonstripped oil. Shahidi and Zhong (2010) reviewed the factors that affecting oxidative stability of oils and mentioned the tocopherols as well as carotenoids retard the oxidation of lipids in the original oils. Furthermore, a sharp increase in the formation of secondary oxidation products (TBARS) was noticed for stripped chia oil during the initial period but after 8 days, changes occurring in the TBARS values were not tested because of advanced oxidation that caused solidification due to polymerization of the tested chia oils. This made it impossible to test both the CD and TBARS. The examination of TBARS during autoxidation showed that stripped chia seed oil was less stable than its nonstripped counterpart. This demonstrates the importance of minor components on oil stability.

\section{Oxidative stability under fluorescent light}

Figure 3 presents the trend for the formation of the primary oxidation products, reflected in $\mathrm{CD}$ values, of both stripped and non-stripped chia seed oils subjected to photooxidation. Results indicated that stripped chia seed oil was significantly more stable than its non-stripped counterpart. This is the reverse of the autoxidation results for the same samples. Similar results were observed in the literature. Abuzaytoun and Shahidi (2006a) as well as $\mathrm{Li}$ et al. (2016) reported that the presence of 


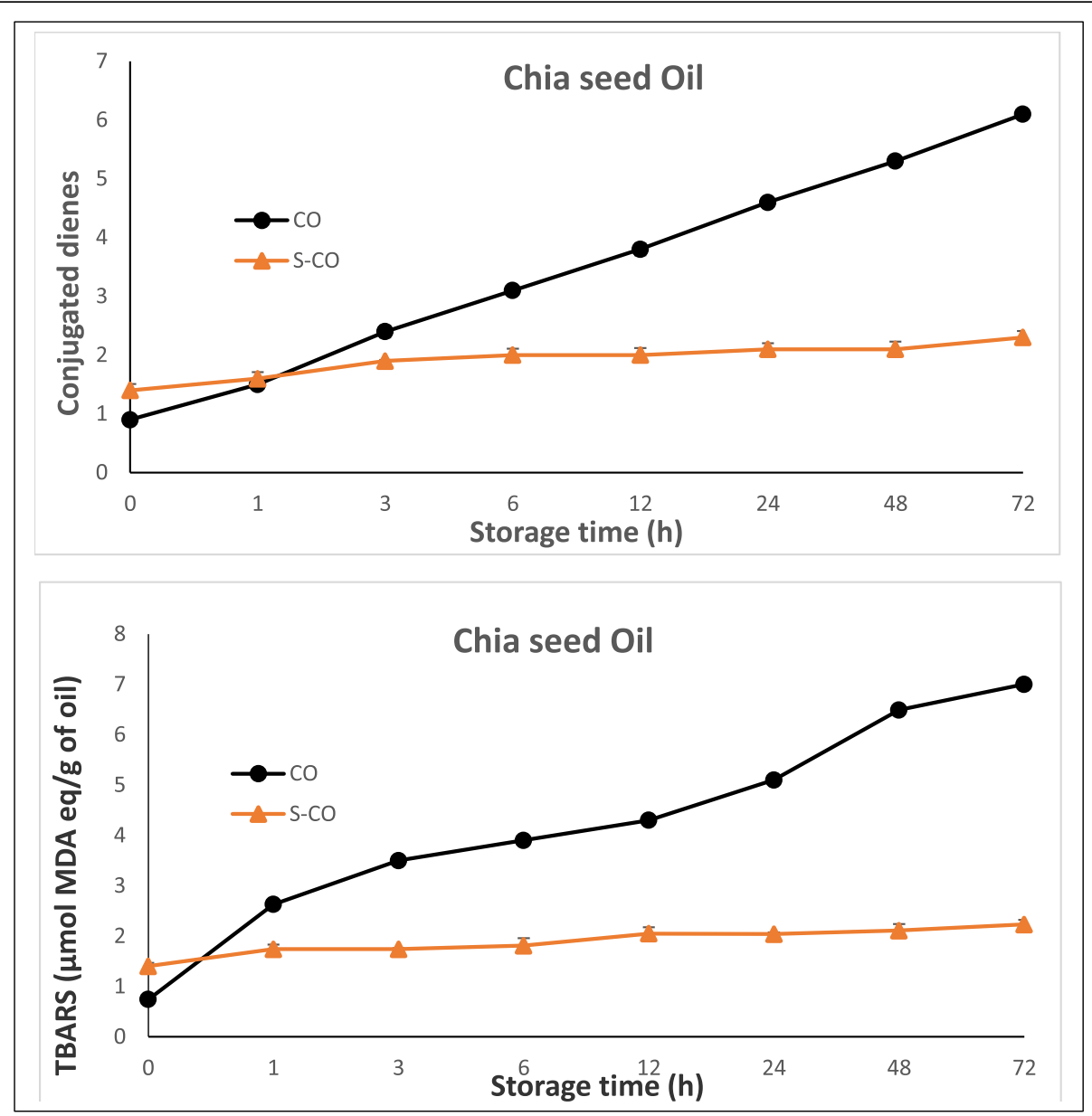

Fig. 3 Conjugated dienes and thiobarbituric acid reactive substances (MDA equivalents) of crude chia oil (CO) and stripped chia oil (S-CO) during $72 \mathrm{~h}$ storage period under fluorescent light at $27^{\circ} \mathrm{C}(P<0.05)$

chlorophylls in non-stripped oils as photosensitizers was contemplated even though they contained high amounts of tocols.

The secondary oxidation products as reflected in TBARS values of non-stripped and stripped chia seed oils under fluorescent light are also shown in Fig. 3. The results indicated that stripped chia seed oil had better stability than non-stripped chia oil, primarily due to the presence of photosensitizers in non-stripped chia oil as was also the case for primary oxidation products.

\section{Conclusions}

This study provided the fatty acid and triacylglycerol compositions of chia seed oil, the latter for the first time. Chia seed oils are important sources of polyunsaturated fatty acids (PUFAs), mainly $\alpha$-linolenic acid as reflected in both the fatty acid composition and most of the TAG profiles. Tocols and pigments, including chlorophylls and carotenoids, also affected oil stability. Thus, chia seed oil can serve as an important source of healthful lipid for inclusion in the daily diet and a functional food ingredient. The information provided in this contribution is expected to facilitate further developments in this area for possible industrial application of chia seed and its oil.

\section{Abbreviations}

TAG: Triacylglycerols; ALA: a-linolenic acid;; EPA: Eicosapentaenoic acid; DHA: Docosahexaenoic acid; FAMEs: Fatty acid methyl esters; GC-FID: Gas chromatography-flame ionization detection; CD: Conjugated dienes; TBARS: Thiobarbituric acid-reactive substances; HPLC: High performance liquid chromatography; PUFA: Polyunsaturated fatty acids; LnLnLn

: Trilinolenin; LnLLn: Linolenoyl-linoleoyl-linolenoylglycerol; LnLnP: Linolenoyllinolenoyl-palmitoylglycerol; LLLn: Linoleoyl-linoleoyl-linolenoylglycerol;

LnOLn: Linolenoyl-oleoyl- linolenoylglycerol; UFA: Unsaturated fatty acids

\section{Acknowledgement}

We are grateful to the Natural Science and Engineering Research Council (NSERC) of Canada for a Discovery Grant to FS. Abrehem Abad thanks the Libyan Ministry of Higher Education \& Scientific Research for a scholarship as well as the Food And Drug Control Center-Libya.

\section{Authors' contributions}

Authors contributed equality to the reported work. The author read and approved the final manuscript. 


\section{Funding}

Authors are grateful to the Natural Sciences and Engineering Research Council of Canada (NSERC) for a Discovery Grant to FS and the Libyan Ministry of Higher Education \& Scientific Research for a scholarship as well as the Food And Drug Control Center-Libya .

\section{Availability of data and materials}

Please contact authors for data request.

\section{Competing interests}

The authors declare that they have no competing interests.

Received: 15 March 2020 Accepted: 8 April 2020

Published online: 29 April 2020

\section{References}

Abad, A., \& Shahidi, F. (2020). A robust stripping method for the removal of minor components from edible oils. Food Production, Processing and Nutrition, 2, 1 .

Abou-Gharbia, H. A., Shahidi, F., Shehata, A. A. Y., \& Youssef, M. M. (1996). Oxidative stability of extracted sesame oil from raw and processed seeds. Journal of Food Lipids, 3(1), 59-72.

Abuzaytoun, R., \& Shahidi, F. (2006a). Oxidative stability of algal oils as affected by their minor components. Journal of Agricultural and Food Chemistry, 54(21), $8253-8260$

Abuzaytoun, R., \& Shahidi, F. (2006b). Oxidative stability of flax and hemp oils. Journal of the American Oil Chemists' Society, 83(10), 855-861.

Alfredo, V. O., Gabriel, R. R., Luis, C. G., \& David, B. A. (2009). Physicochemical properties of a fibrous fraction from chia (Salvia hispanica L.). LWT- Food Science and Technology, 42(1), 168-173.

Ali, M., Gafur, M., Rahman, M., \& Ahmed, G. (1985). Variations in fat content and lipid class composition in ten different mango varieties. Journal of the American Oil Chemists' Society, 62(3), 520-523.

Ayerza, R. (1995). Oil content and fatty acid composition of chia (Salvia hispanica L.) from five northwestern locations in Argentina. Journal of the American Oil Chemists' Society, 72, 1079-1081.

Ayerza, R., \& Coates, W. (2011). Protein content, oil content and fatty acid profiles as potential criteria to determine the origin of commercially grown chia (Salvia hispanica L.). Industrial Crops and Products, 34(2), 1366-1371.

Ayerza, R. H., \& Coates, W. (2004). Composition of chia (Salvia hispanica) grown in six tropical and subtropical ecosystems of South America. Tropical Science, 44(23), 131-135.

Bakowska-Barczak, A. M., Schieber, A., \& Kolodziejczyk, P. (2009). Characterization of Canadian black currant (ribes nigrum L.) seed oils and residues. Journal of Agricultural and Food Chemistry, 57(24), 11528-11536.

Blekas, G., Tsimidou, M., \& Boskou, D. (1995). Contribution of a-tocopherol to olive oil stability. Food Chemistry, 52(3), 289-294.

Capitani, M. I., Spotorno, V., Nolasco, S. M., \& Tomás, M. C. (2012). Physicochemical and functional characterization of by-products from chia (Salvia hispanica L.) seeds of Argentina. LWT- Food Science and Technology, 45(1), 94-102.

Coates, W., \& Ayerza, R. (1998). Commercial production of chia in northwestern Argentina. Journal of the American Oil Chemists' Society, 75(10), 1417-1420.

Commission of the European Communities. (2009). Commission regulation (EC) 827/2009. Official Journal of the European Union, 52, 12-13.

da Silva Marineli, R., Moraes, É. A., Lenquiste, S. A., Godoy, A. T., Eberlin, M. N., \& Maróstica Jr., M. R. (2014). Chemical characterization and antioxidant potential of Chilean chia seeds and oil (Salvia hispanica L.). LWT- Food Science and Technology, 59(2), 1304-1310.

Ganesan, B., Brothersen, C., \& McMahon, D. J. (2014). Fortification of foods with omega-3 polyunsaturated fatty acids. Critical Reviews in Food Science and Nutrition, 54(1), 98-114

Haddad, R., Sparrapan, R., \& Eberlin, M. N. (2006). Desorption sonic spray ionization for (high) voltage-free ambient mass spectrometry. Rapid Communications in Mass Spectrometry: An International Journal Devoted to the Rapid Dissemination of Up-to-the-Minute Research in Mass Spectrometry, 20(19), 2901-2905.

Haytowitz, D. B., Ahuja, J. K. C., Thomas, R., Nickle, M., Roseland, J. M., Williams, J. R..... \& Patterson, K. Y. (2011). USDA national nutrient database for standard reference, release 24. US Department of Agriculture: Washington, DC, USA.
Ixtaina, V. Y., Martínez, M. L., Spotorno, V., Mateo, C. M., Maestri, D. M., Diehl, B. W., \& Tomás, M. C. (2011). Characterization of chia seed oils obtained by pressing and solvent extraction. Journal of Food Composition and Analysis, 24(2), 166-174.

Khan, M. A., \& Shahidi, F. (2002). Photooxidative stability of stripped and nonstripped borage and evening primrose oils and their emulsions in water. Food chemistry, 79(1), 47-53.

Li, Q., Wang, J., \& Shahidi, F. (2016). Chemical characteristics of cold-pressed blackberry, black raspberry, and blueberry seed oils and the role of the minor components in their oxidative stability. Journal of Agricultural and Food Chemistry, 64(26), 5410-5416.

Lísa, M., \& Holčapek, M. (2008). Triacylglycerols profiling in plant oils important in food industry, dietetics and cosmetics using high-performance liquid chromatography-atmospheric pressure chemical ionization mass spectrometry. Journal of Chromatography A, 1198, 115-130.

Lu, Y., \& Foo, L. Y. (2002). Polyphenolics of Salvia-a review. Phytochemistry, 59(2), 117-140

Miraliakbari, H., \& Shahidi, F. (2008). Oxidative stability of tree nut oils. Journal of Agricultural and Food Chemistry, 56(12), 4751-4759.

Neff, W., Mounts, T., Rinsch, W., \& Konishi, H. (1993). Photooxidation of soybean oils as affected by triacylglycerol composition and structure. Journal of the American Oil Chemists' Society, 70(2), 163-168.

Neff, W., Mounts, T., Rinsch, W., Konishi, H., \& El-Agaimy, M. (1994). Oxidative stability of purified canola oil triacylglycerols with altered fatty acid compositions as affected by triacylglycerol composition and structure. Journal of the American Oil Chemists' Society, 71(10), 1101-1109.

Neff, W. E., Mounts, T. L., \& Rinsch, W. M. (1997). Oxidative stability as affected by triacylglycerol composition and structure of purified canola oil triacylglycerols from genetically modified normal and high stearic and lauric acid canola varieties. LWT- Food Science and Technology, 30(8), 793-799.

Nijveldt, R. J., van Nood, E., van Hoorn, E. C., Boelens, P. G., van Norren, K., \& van Leeuwen, P. A. (2001). Flavonoids: A review of probable mechanisms of action and potential applications. The American Journal of Clinical Nutrition, 74(4), 418-425.

Porter, N. A., Caldwell, S. E., \& Mills, K. A. (1995). Mechanisms of free radical oxidation of unsaturated lipids. Lipids, 30(4), 277-290.

Rahman, M. J., de Camargo, A. C., \& Shahidi, F. (2017). Phenolic and polyphenolic profiles of chia seeds and their in vitro biological activities. Journal of Functional Foods, 35, 622-634.

Reyes-Caudillo, E., Tecante, A., \& Valdivia-López, M. A. (2008). Dietary fibre content and antioxidant activity of phenolic compounds present in Mexican chia (Salvia hispanica L.) seeds. Food Chemistry, 107(2), 656-663.

Rincon-Cervera, M. A., Valenzuela, R., Hernandez-Rodas, M. C., Barrera, C., Espinosa, A., Marambio, M., \& Valenzuela, A. (2016). Vegetable oils rich in alpha linolenic acid increment hepatic n-3 LCPUFA, modulating the fatty acid metabolism and antioxidant response in rats. Prostaglandins. Leukotrienes and Essential Fatty Acids (PLEFA), 111, 25-35.

Segura-Campos, M. R., Ciau-Solís, N., Rosado-Rubio, G., Chel-Guerrero, L., \& Betancur-Ancona, D. (2014). Physicochemical characterization of chia (Salvia hispanica) seed oil from Yucatán, Mexico. Agricultural Sciences, 5(3), 220-226.

Shahidi, F., \& Shukla, V. K. S. (1996). Nontriacylglycerol constituents of fats and oils. Inform-International News on Fats Oils and Related Materials, 7(11), 1227-1232.

Shahidi, F., \& Zhong, Y. (2010). Lipid oxidation and improving the oxidative stability. Chemical Society Reviews, 39(11), 4067-4079.

Tuberoso, C. I., Kowalczyk, A., Sarritzu, E., \& Cabras, P. (2007). Determination of antioxidant compounds and antioxidant activity in commercial oilseeds for food use. Food Chemistry, 103(4), 1494-1501.

Valenzuela, R., Bascuñán, K., Chamorro, R., Barrera, C., Sandoval, J., Puigrredon, C., ... \& Valenzuela, A. (2015). Modification of docosahexaenoic acid composition of milk from nursing women who received alpha linolenic acid from chia oil during gestation and nursing. Nutrients, 7(8), 6405-6424.

Wanasundara, U. N., \& Shahidi, F. (1997). Positional distribution of fatty acids in triacylglycerols of seal blubber oil. Journal of Food Lipids, 4(1), 51-64.

Warner, K., Frankel, E. N., \& Mounts, T. L. (1989). Flavor and oxidative stability of soybean, sunflower and low erucic acid rapeseed oils. Journal of the American Oil Chemists' Society, 66(4), 558-564.

\section{Publisher's Note}

Springer Nature remains neutral with regard to jurisdictional claims in published maps and institutional affiliations. 